\title{
Slumbering mucosal immune response in the cervix of human papillomavirus DNA-positive and -negative women
}

\author{
SOPHIA BRISMAR WENDEL ${ }^{1}$, TOVE KALDENSJÖ ${ }^{2}$, PERNILLA PETERSON ${ }^{2}$, \\ SONIA ANDERSSON ${ }^{1}$, KRISTINA BROLIDEN $^{2}$ and TAHA HIRBOD ${ }^{2}$ \\ ${ }^{1}$ Division of Obstetrics and Gynecology, Department of Clinical Science, Intervention and Technology, Huddinge; \\ ${ }^{2}$ Center for Molecular Medicine, Unit of Infectious Diseases, Department of Medicine Solna, \\ Karolinska Institutet, Karolinska University Hospital, Stockholm, Sweden
}

Received June 8, 2010; Accepted July 23, 2010

DOI: 10.3892/ijo_00000810

\begin{abstract}
Persistent human papillomavirus (HPV) infection is a prerequisite for cervical cancer and results from bypassing the local immune response. Twenty-four volunteers underwent an ectocervical biopsy, Pap smear, tests for sexually transmitted infections including HIV and HPV genotyping. All answered a questionnaire regarding medical history. Repeat Pap smear and HPV genotyping was performed 9-26 months later. Quantitative reverse transcriptase (qRT-)PCR was used to assess expression of CD3, CD4, CD8, CD19, CD27, IL-2, IL-12, IL-4, IL-10, IL-17, HLA-DR $\alpha$, TGFß, IFN $\gamma$, PD-1, PD-L1, CTLA-4, LAG3, IgA, IgG, CCR5, CCL5/RANTES and the IL-7 receptor in the biopsies. Eleven of 24 volunteers were HPV DNA-positive at baseline. Four of 10 were infected with a persistent HPV genotype at followup. All target molecules were successfully amplified and quantified except for IL-4. We found no difference in mRNA expression of these molecules when comparing HPV DNApositive and -negative women, neither when comparing persistently infected individuals or those who cleared the infection. However, mRNA expression of the B cell phenotypic marker CD19 was higher in women using hormonal contraception than those not $(\mathrm{p}<0.05)$. HPV infection does not evoke a local inflammatory immune response in the ectocervix measurable with qRT-PCR. Hormonal contraception may influence $\mathrm{B}$ cell activity in the cervix.
\end{abstract}

\section{Introduction}

Infection with oncogenic human papillomavirus (HPV) is a crucial factor in the development of cervical intraepithelial neoplasia (CIN) and cancer $(1,2)$. HPV is a common sexually

Correspondence to: Dr Sophia Brismar Wendel, ${ }^{3}$ Present address: Department of Obstetrics and Gynecology, Sykehuset i Østfold, Fredrikstad, N-1603 Fredrikstad, Norway

E-mail: sophia.brismar@ki.se

Key words: immune response, innate, adaptive, cervix, human papillomavirus, HIV, cytokine, female genital tract transmitted virus with a cumulative life-time risk of any HPV-type of $80 \%$, although only a small fraction of infected women progress to invasive cancer of the cervix (3-5). Failure of the host immune response to clear the HPV infection contributes to carcinogenesis, as suggested by the increased prevalence of HPV infection, CIN and cervical cancer in individuals with impaired cell-mediated immunity such as that in patients with HIV/AIDS, organ transplants and iatrogenic immunosuppression $(6,7)$. The immunological barrier of the cervical mucosa is predominately regulated in the lamina propria, which contains plasma cells, antigen-presenting cells (dendritic cells), natural killer cells as well as helper and cytotoxic T lymphocytes. Successful regression of HPV infection occurs in the presence of local pro-inflammatory (Th1) cytokine expression (8-10) and CD4 ${ }^{+} \mathrm{T}$ cells as evident in immunohistological studies of HPV-induced warts (11), and a systemic lymphoproliferative response to HPV E7 protein (12). Therefore, cytokine-mediated immune responses may be a critical factor in HPV clearance.

Cytokines are usually expressed at low levels in a paraand autocrine fashion, but the small size of relevant tissue samples limits the opportunity to extract and analyze these proteins. Consequently, the detection of cytokine expression at the mRNA level has become an attractive approach, which we selected for this study in the form of semi-quantitative real-time reverse transcriptase PCR (RT-PCR) technology (13).

A dogmatic and simplified view of cytokine secretion divides the options into studies of pro-inflammatory cytokines that stimulate cell-mediated responses (Th1) or immuneinhibitory, tumor-permissive cytokines that mediate humoral immunity (Th2). The pro-inflammatory group includes interleukin-2 (IL-2) -12 and -17, interferon- $\gamma$ (IFN $\gamma$ ), regulated upon activation normal $\mathrm{T}$ cell expressed and secreted (RANTES)/C-C chemokine ligand 5 (CCL5), as well as expression of $\mathrm{C}-\mathrm{C}$ chemokine receptor 5 (CCR5) and HLA-DR. Those considered to be anti-inflammatory are IL-4, IL-10 and transforming growth factor- $\beta$ (TGFß) $(14,15)$. IL-17 also promotes mucosal expression of endogenous anti-microbial peptides, such as defensins, which act as natural antibiotics and exhibit chemotactic activity (16). Scott et al demonstrated a local Th1 response pattern (non-quantitative) in 
Table I. Entry characteristics.

\begin{tabular}{|c|c|c|c|c|}
\hline \multirow[b]{2}{*}{ Entry data } & \multirow[b]{2}{*}{ All } & \multicolumn{2}{|c|}{ HPV status } & \multirow[b]{2}{*}{ p-value ${ }^{a}$} \\
\hline & & HPV-positive & HPV-negative & \\
\hline Number of women, $\mathrm{N}(\%)$ & 24 & $11(46)$ & $13(54)$ & 0.56 \\
\hline Age (median) [range], years & $32[24-50]$ & $31[24-46]$ & $32[26-50]$ & 0.66 \\
\hline Current smoker, $\mathrm{N}(\%)$ & $5(21)$ & $2(18)$ & $3(23)$ & 0.58 \\
\hline Hormonal contraception, $\mathrm{N}(\%)$ & $11(46)$ & $5(45)$ & $6(46)$ & 0.98 \\
\hline Oral contraception, $\mathrm{N}(\%)$ & $7(29)$ & $5(45)$ & $2(15)$ & 0.18 \\
\hline Progesterone IUD, N (\%) & $4(17)$ & 0 & $4(31)$ & 0.10 \\
\hline Condom use $\geq 50 \%, \mathrm{~N}(\%)$ & $7(29)$ & $4(36)$ & $3(23)$ & 0.66 \\
\hline New sex partner previous 12 months, $\mathrm{N}(\%)$ & $6(25)$ & $3(27)$ & $3(23)$ & 1.00 \\
\hline Ever pregnant, N (\%) & $13(57)$ & $4(40)$ & $9(69)$ & 0.16 \\
\hline Additional cervical condition ${ }^{\mathrm{b}}, \mathrm{N}(\%)$ & $5(21)$ & $2(18)$ & $3(23)$ & 1.00 \\
\hline Previous CIN1+, N (\%) & $2(8.7)$ & 0 & $2(15)$ & 0.25 \\
\hline HSV-2 seropositive, $\mathrm{N}(\%)$ & $4(17)$ & $1(9)$ & $3(23)$ & 0.29 \\
\hline Preovulatory menstrual phase, N (\%) & $2(8.7)$ & $1(10)$ & $1(7.7)$ & 0.95 \\
\hline Postovulatory menstrual phase, N (\%) & $10(43)$ & $4(40)$ & $6(46)$ & 0.95 \\
\hline
\end{tabular}

${ }^{a}$ Mann-Witney $\mathrm{U}$ or $\chi^{2} /$ Fischer's exact test; ${ }^{\text {b}}$ Yeast infection, bacterial vaginosis, or low-grade squamous intraepithelial lesion/atypical squamous cells of uncertain significance in the first Pap smear.

cervical brushings from women who cleared their HPV infection (8). A few studies have shown that mixed inflammatory states or dysplasia of the cervix involves increased mRNA expression of Th1 cytokines (17-19). In contrast, amounts of Th2 response cytokines including IL-4 and IL-10 are increased in HIV-positive HPV-co-infected persons compared to those infected with HPV alone or not infected, and such an increase may contribute to the inability to clear HPV infection (20-22).

Immunoregulatory receptors, such as the IL-7 receptor (IL-7R), the programmed cell death receptor 1 (PD-1), its ligand PD-L1, cytotoxic T-lymphocyte antigen 4 (CTLA-4) and lymphocyte-activation gene 3 (LAG-3) are considered to be suppressors of $\mathrm{T}$ cell activation and/or participants in $\mathrm{T}$ cell memory (IL-7R) $(23,24)$. Moreover, the impact of these immunoregulatory receptors and ligands on chronic infection caused by HIV, hepatitis B and hepatitis C has generated growing interest. PD-1 is up-regulated on activated $\mathrm{T}$ cells specific for chronic viral infections in humans but not $\mathrm{T}$ cells specific for non-persisting vaccinia or influenza viruses (reviewed in ref. 25). Blockade of PD-1 in a macaque model enhanced $\mathrm{T}$ cell immunity, as well as memory B cell proliferation, decreased viral load and prolonged survival (26). Exhausted T cells have been stained for PD-1, LAG-3 and CTLA-4 among several other inhibitory receptors in a complex pattern, yet their levels of expression seem to vary with the severity of viral infection (27). Expression of these regulatory receptors and ligands has not yet been studied in HPV.

Here we have focused on the mRNA expression of several cytokines as well as on phenotypic markers including CD3, CD4 and CD8 for T cells, CD19 for B cells, and CD27 as a memory cell marker at the local site (28-30). CD4 and CD8 have been quantified using RT-PCR in the cervical samples of patients with HPV-genotyped CIN (31), but this is the first report of CD4 and CD8 mRNA expression in HPV DNApositive women without CIN. Our results present a comprehensive analysis of the cytokines and phenotypic markers on cells involved in the local mucosal immunity in the genital tract of HPV DNA-positive and -negative women without CIN.

\section{Materials and methods}

Study subjects. A total of 24 subjectively healthy female volunteers were enrolled from March 2007 through September 2008 at the Division of Obstetrics and Gynecology, Karolinska University Hospital Huddinge, Sweden, after ethical approval and written informed consent were obtained. All subjects underwent a pelvic exam with collection of samples for cytological diagnosis, HPV DNA analysis, diagnosis of chlamydia trachomatis and neisseria gonorrhea. An ectocervical biopsy was also collected from each woman. Blood samples were drawn for HIV and herpes simplex virus (HSV) serological tests. All assays were performed at the accredited microbiological laboratory service at the hospital. Each woman also completed a questionnaire regarding previous medical conditions, reproductive history, menstrual cycle, contraception, smoking and sexual partnership status, as compiled in Table I. Nine to 26 months (median 23.8) later women were drafted for a second pelvic exam, cervical cytological sampling and HPV DNA testing. Nineteen (79\%) of the 24 women completed the study, while five were lost to followup due to withdrawal (four) or pregnancy (one).

Cytology. Cells collected from the ectocervix with a plastic spatula and from the endocervix with a plastic brush were prepared as conventional Pap smears. The cytobrush was 
Table II. Study subjects at inclusion and follow-up.

\begin{tabular}{|c|c|c|c|c|c|c|c|}
\hline Id code & Age & Hormonal exposure & 1st Pap smear & 1st HPV status & $\begin{array}{l}\text { Time between } \\
\text { visits (months) }\end{array}$ & 2nd Pap smear & 2nd HPV status \\
\hline 1 & 50 & Postovulatory & Normal & neg & 9.7 & Normal & neg \\
\hline 2 & 41 & Progesterone IUD & Normal & neg & 9.6 & Normal & neg \\
\hline 3 & 36 & Preovulatory & Normal & neg & $-c$ & - & - \\
\hline 4 & 31 & Progesterone IUD & Normal, yeast & neg & 9.4 & Normal & neg \\
\hline 5 & 41 & Progesterone IUD & Normal, yeast & neg & - & - & - \\
\hline 6 & 37 & Postovulatory & Normal & neg & 25.2 & Normal & neg \\
\hline 7 & 37 & $\begin{array}{l}\text { Copper IUD, } \\
\text { postovulatory }\end{array}$ & Normal & neg & - & - & - \\
\hline 8 & 32 & Postovulatory & Normal & neg & 25.1 & Normal & neg \\
\hline 9 & 31 & Progesterone IUD & Normal, BV & neg & - & - & - \\
\hline 10 & 31 & Combined OC & Normal & neg & 20.8 & Normal & neg \\
\hline 11 & 30 & Postovulatory & Normal & neg & 25.2 & Normal & HPV 81 \\
\hline 12 & 26 & Postovulatory & Normal & neg & 24.3 & Normal & HPV 53, 61 \\
\hline 13 & 26 & Combined OC & Normal & neg & 26.7 & Normal & neg \\
\hline 14 & 41 & Oral contraception ${ }^{\mathrm{b}}$ & Normal & HPV 79 & 9.1 & Normal & HPV 70 \\
\hline 15 & 36 & Preovulatory & Normal & HPV 55 & 10.6 & Normal & HPV 55 \\
\hline 16 & 26 & Combined OC & Normal & HPV 55 & 25.9 & Normal & neg \\
\hline 17 & 46 & Postovulatory & Normal & HPV 52 & 25.2 & Normal & neg \\
\hline 18 & 41 & Postovulatory & Normal & HPV 16 & 24.1 & Normal & neg \\
\hline 19 & 37 & Postovulatory & Normal & HPV 51 & 25.8 & Normal & neg \\
\hline 20 & 31 & Combined OC & Normal & $\begin{array}{c}\text { HPV CP6108, } 51 \\
\mathbf{5 9 , 5 3 , 6 8 , 7 3}\end{array}$ & 10.3 & Normal & HPV 51, 53, 73 \\
\hline 21 & 30 & Postovulatory & LSIL & HPV 33 & 23.8 & Normal & neg \\
\hline 22 & 29 & Combined OC & Normal & HPV 35, 39 & - & - & - \\
\hline 23 & 25 & Unknown & Normal & HPV 39 & 23.8 & Normal & HPV 39 \\
\hline 24 & 24 & Combined OC & ASCUS & $\begin{array}{l}\text { HPV 16, 31, } \\
\mathbf{3 3}, 70\end{array}$ & 10.6 & Normal & $\begin{array}{l}\text { HPV 18, 31, } \\
\text { IS39 }\end{array}$ \\
\hline
\end{tabular}

${ }^{a}$ Women with intact ovulation have their menstrual cycle phase at the first visit recorded in the column hormonal exposure. ${ }^{\mathrm{b}}$ Uses high-dose progesterone only contraceptive pill (anovulation). 'Lost to follow-up. HPV, human papillomavirus (high-risk types in bold); OC, oral contraception; IUD, intrauterine device; BV, bacterial vaginosis; LSIL, low-grade squamous intraepithelial lesion; ASCUS, atypical squamous cells of uncertain significance; CIN, cervical intraepithelial neoplasia.

placed in $1 \mathrm{ml}$ of sterile saline suspension for HPV genotyping. Blinded cytological evaluation was performed by a pathologist. According to Swedish recommendations, cases of koilocytosis without signs of dysplasia are reported as non-pathologic. The cytological diagnoses were based on the Bethesda nomenclature (32).

HPV DNA extraction and linear array. After the cytobrush saline suspension was centrifuged, the cell pellet was lysed by using the Total Nucleic Acid Isolation kit (Roche, Basel, Switzerland). DNA was extracted with the MagNA Pure LC robot and analyzed with the Linear Array HPV genotyping test (both procedures by Roche). Details of this method have been published (33). The Linear Array test is a PCR- and probe hybridization-based genotyping assay covering 37 HPV types including 12 high-risk HPV types (16, 18, 31, 33, $35,39,45,51,52,56,58,59), 6$ probable high-risk HPV types $(26,53,66,68,73,82)$ and 19 low-risk or undeter- 
a

CD3

CD4

CD8

CD27

CD19
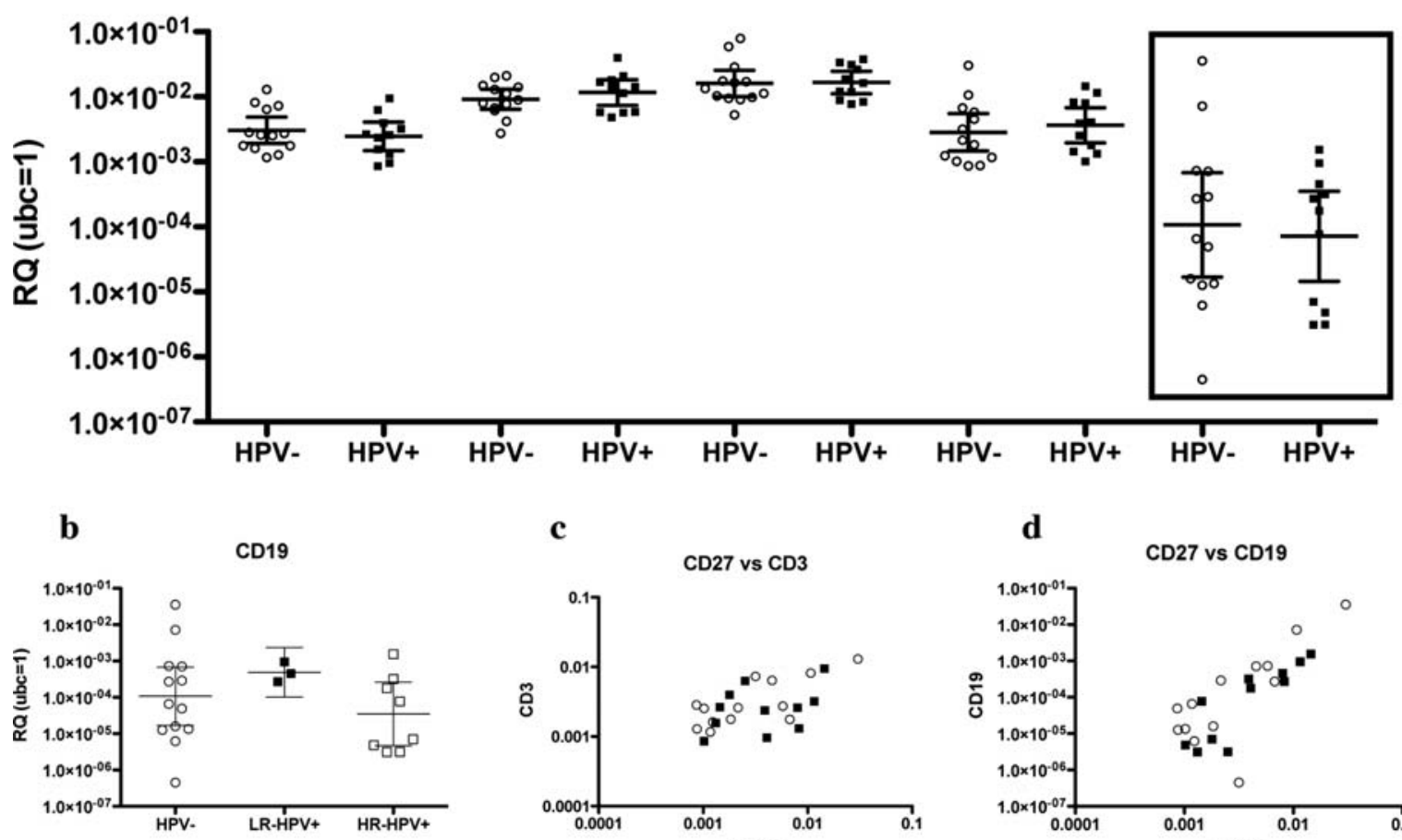

$\mathbf{c}$

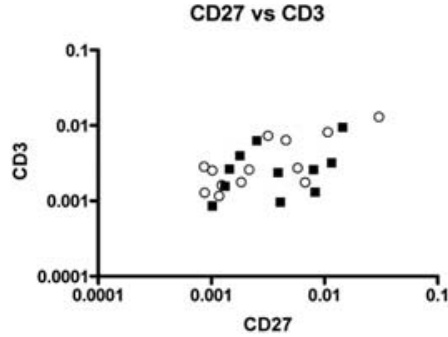

d

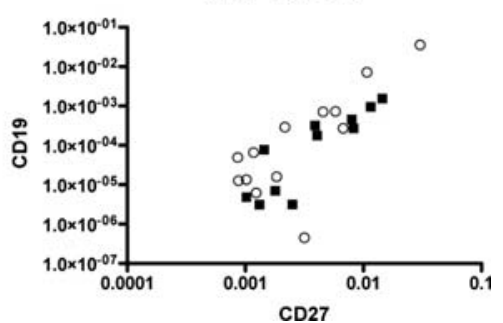

Figure 1. (a) Expression of phenotypic cell markers in HPV DNA-negative (HPV-) (circles) and HPV DNA-positive (HPV+) (boxes) individuals. Lines and bars depict geometric means with a 95\% confidence interval. (b) Expression of CD19 in HPV (circles), low-risk $\mathrm{HPV}^{+}\left(\mathrm{LR}^{-} \mathrm{HPV}^{+}\right)$(filled boxes) and highrisk $\mathrm{HPV}^{+}\left(\mathrm{HR}^{-} \mathrm{HPV}^{+}\right)$(clear boxes) women. Lines and bars depict geometric means with $95 \%$ confidence interval, $\mathrm{p}=0.25$. (c) Correlations between $\mathrm{CD} 27$ and $\mathrm{T}$ cell marker $\mathrm{CD} 3$ in $\mathrm{HPV}^{-}$(circles) $\left(\mathrm{p}<0.001, \mathrm{r}^{2}=0.72\right)$ and $\mathrm{HPV}^{+}$(boxes) $(\mathrm{p}=0.10)$ individuals. (d) Correlations between $\mathrm{CD} 27$ and phenotypic $\mathrm{B}$ cell marker CD19 in $\mathrm{HPV}^{-}($circles $)\left(\mathrm{p}<0.001, \mathrm{r}^{2}=0.94\right)$ and $\mathrm{HPV}^{+}$(boxes) $\left(\mathrm{p}<0.001, \mathrm{r}^{2}=0.88\right)$ individuals.

mined HPV types $(6,11,40,42,54,55,61,62,64,67,69$, 70, 71, 72, 81, 83, 84, IS39, CP6108) (34). Linear Array uses biotinylated primers within the consensus L1 region of the HPV genome.

Detection and quantification of cytokine mRNA. Biopsies were taken by a single investigator (S.A.) from the superior ectocervix outside the transformation zone, immediately transferred to RNAlater buffer (Qiagen, Hilden, Germany), and stored at $-70^{\circ} \mathrm{C}$. The biopsies were thawed and disrupted in lysis buffer with a mechanical rotor, and RNA was extracted according to the manufacturer's protocol (the kit RNeasy, Qiagen). RNA was converted in equal dilutions to cDNA in a single reverse transcriptase reaction using superscript II reverse transcriptase (Invitrogen, Life Technologies Corporation, Carlsbad, CA, USA) and random hexanucleotide primers (Roche). The cDNA was stored at $-20^{\circ} \mathrm{C}$. Amplification of ubiquitin C (UBC), CD3, CD4, CD8, CD19, CD27, IL-2, IL-12a, IL-4, IL-10, IL-17a, HLA-DR $\alpha$, TGFß, IFN $\gamma$, PD-1, PD-L1, CTLA-4, LAG3, IgA constant heavy $\operatorname{IgG}_{\text {constant heavy }}$, CCR5, CCL5/RANTES and IL-7 receptor (IL-7R) cDNA was performed using the ABI PRISM 7500 sequence detection system and commercial FAM ${ }^{\mathrm{TM}}$ dye-labeled TaqMan MGB probes and primers (Applied Biosystems Inc, Foster City, CA, USA). UBC was chosen as endogenous control after a dilution series testing UBC, 18sRNA, and GAPDH revealed that UBC was the most constant highly expressed gene in our samples. Each sample and control was run in triplicates. The relative quantity of target cDNA was computed using the comparative threshold $(\mathrm{Ct})$ method (35). Ct values for target cDNA were normalized to UBC $\left(\mathrm{Ct}_{\mathrm{UBC}}-\mathrm{Ct}_{\text {target }}\right)$ and amounts of cDNA were computed through $\ln$-transformation $\left(2^{-\mathrm{dCt}}\right)$. This can be read out as number of target gene copies for each copy of UBC.

Statistical analysis. Data were analyzed with the software Statistica 8.0 (Statsoft Inc., Tulsa, OK, USA) and GraphPad Prism 4.00 (GraphPad Software Inc, La Jolla, CA, USA). Pearson's Chi-square and Fischer's exact test were used to compare proportions and Student's t-test to compare ages between groups. Data were not normally distributed even after logarithmic transformation therefore a non-parametric Mann-Witney U test was used to compare two groups and Kruskal-Wallis ANOVA to compare multiple groups, and Spearman rank-order correlation test to assess correlations. Multivariate logistic regression was performed to analyze effects of clinical parameters on CD19 expression, categorizing CD19 mRNA expression above or below median level. All tests were two-sided and differences considered significant at $\mathrm{p}<0.05$.

\section{Results}

Distribution of HPV genotypes and cytological findings. At inclusion, a total of 22 of 24 (92\%) women had cytological results within normal limits, one had atypical squamous cells 
of uncertain significance (ASCUS) and one woman had a low-grade squamous intraepithelial lesion (LSIL). Eleven (46\%) were positive for some HPV type, of whom 8 (33\%) carried high-risk HPV types (Table II). Four women were HSV-2 seropositive and one of these had a reported history of genital herpes. None of the women was diagnosed with HIV, chlamydia or gonorrheal genital infection, although one woman's results from chlamydia PCR analysis and N. gonorrhea culture were missing. Two women had additional findings of yeast infection, and one had signs of bacterial vaginosis. These three women, including the two with minor cytological lesions, were designated as a group with an additional cervical condition. None of the HSV-2 seropositive women had ongoing genital lesions, and were not included in this group. No relevant differences in sexual or reproductive histories were noted between HPV-positive and -negative subjects (Table I). At follow-up, all women had normal findings in the cervical cytology sample. One woman had acquired genital herpes and seroconverted to HSV-2 (id code no. 12). Four (21\%) women still carried at least one persistent HPV type, while three had acquired a new HPV type and five $(26 \%)$ had succeeded in clearing the virus. Seven women were still HPV DNA-negative at follow-up. There were no significant differences found between these groups of HPV clearance status with regard to surveys of hormonal exposure, smoking, contraceptive methods, sexual and reproductive history or age (data not shown).

Expression of phenotypic markers. Expression of the $\mathrm{T}$ phenotypic markers CD3, CD4 and CD8, and B phenotypic markers CD19 and CD27 was calculated in relative quantity compared to the endogenous control UBC (Fig. 1). None of these phenotypic markers of HPV-positive women differed significantly from those of the HPV-negative group ( $\mathrm{p}>0.5)$. CD19 expression was widely dispersed in HPV DNA-negative women and women positive for high-risk and low-risk HPV DNA (Fig. 1), raising the question whether the outliers represent different compositions of B cells, with very high or low relative frequencies of CD19-negative cells such as memory B cells and plasma cells. Since no markers specific for human plasma cells are available, quantities of the memory B cell marker CD27 were evaluated and found to correlate linearly with CD19 (Fig. 1). Not forgetting that CD27 is also expressed by $\mathrm{T}$ cells, we tested further and found that the total CD27 expressed here correlated better with the amount of CD19 from B cells than with CD3 from T cells (Fig. 1). Interestingly, all four women with persistent HPV infection at follow-up displayed CD19 mRNA levels above the median $(\mathrm{p}=0.06)$. None of the other phenotypic markers differed significantly between groups of HPV status at follow-up (data not shown).

Expression of immunoglobulins. Expression of immunoglobulin mRNA was used as a marker for plasma cell presence. Immunoglobulin A (IgA) was detectable in all women, but immunoglobulin $\mathrm{G}$ ( $\mathrm{IgG}$ ) was absent in four of those who were HPV-negative (Fig. 2). There was no difference in expression of $\mathrm{IgA}$ or IgG in HPV DNA-negative women and women positive for high-risk and low-risk HPV DNA (Fig. 2). IgA expression correlated well with that of $\operatorname{IgG}$ in

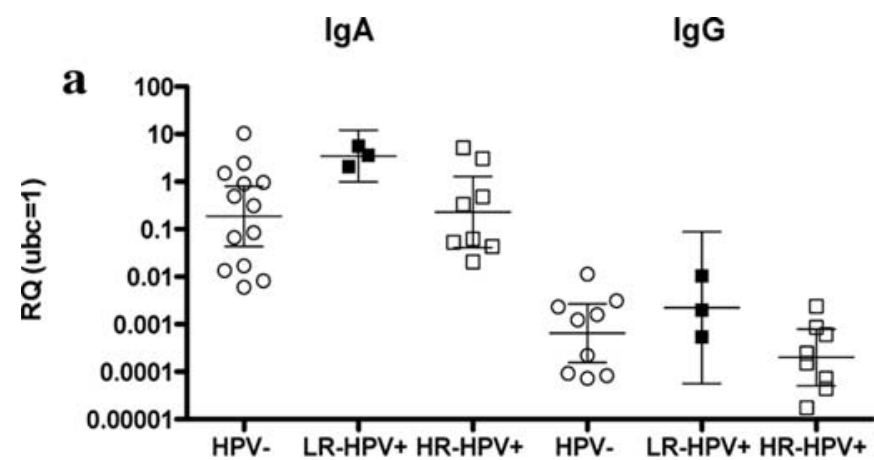

b

$\lg A$ vs $\lg G$

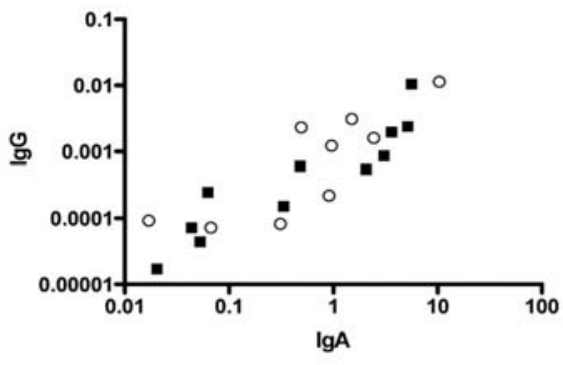

c

CD19 vs $\lg A$ and $\lg G$

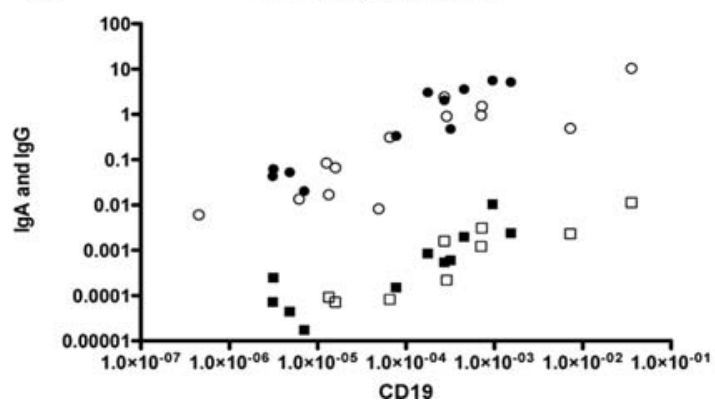

Figure 2. (a) Expression of IgA and IgG mRNA in HPV- (circles), low-risk $\mathrm{HPV}^{+}\left(\mathrm{LR}^{\left.-\mathrm{HPV}^{+}\right)}\right.$(filled boxes) and high-risk $\mathrm{HPV}^{+}\left(\mathrm{HR}^{-} \mathrm{HPV}^{+}\right)$(clear boxes) women. Lines and bars depict geometric mean with $95 \%$ confidence interval, $\mathrm{p}>0.05$ between groups for both $\operatorname{IgA}$ and $\operatorname{IgG}$. (b) $\operatorname{IgA}$ and $\operatorname{IgG}$ expression strongly correlated in HPV- (circles) $\left(\mathrm{p}<0.001, \mathrm{r}^{2}=0.93\right)$ and HR$\mathrm{HPV}^{+}\left(\mathrm{LR}\right.$ and HR combined; boxes) $\left(\mathrm{p}<0.0001, \mathrm{r}^{2}=0.97\right)$ women. All values are in relation to $\mathrm{UBC}(=1)$. (c) IgA expression correlated with CD19 in $\mathrm{HPV}^{-}$(clear circles) and $\mathrm{HPV}^{+}$women (LR and $\mathrm{HR}$ combined; clear boxes) $\left(\mathrm{p}<0.001, \mathrm{r}^{2}=0.90\right.$ and $\mathrm{p}<0.001 \mathrm{r}^{2}=0.75$, respectively) as did $\operatorname{IgG}$ expression with CD19 $\mathrm{HPV}^{-}$(filled circles; $\mathrm{p}<0.001, \mathrm{r}^{2}=0.93$ ) and $\mathrm{HPV}^{+}$ (filled boxes; $\mathrm{p}=0.046, \mathrm{r}^{2}=0.37$ ) women. All values are in relation to $\mathrm{UBC}$ $(=1)$.

all women (Fig. 2) and immunoglobulin expression correlated linearly with amounts of both CD19 (Fig. 2) and CD27 (data not shown), although neither CD19 nor CD27 should be expressed by plasma cells. No difference was found in expression of IgA or IgG mRNA between groups of HPV status at follow-up (data not shown).

Cytokine profiles, immunoregulatory receptors and ligands. As Fig. 3 depicts, expression of the pro-inflammatory cytokines IL-2, IL-12, IL-17 and IFN $\gamma$, RANTES/CCL5, its receptor CCR5, and HLA-DR was similar in the HPV DNAnegative and -positive women. Nor was any difference evident when sub-grouping HPV-positive women into low-risk or high-risk HPV carriers, nor between groups of HPV status at 


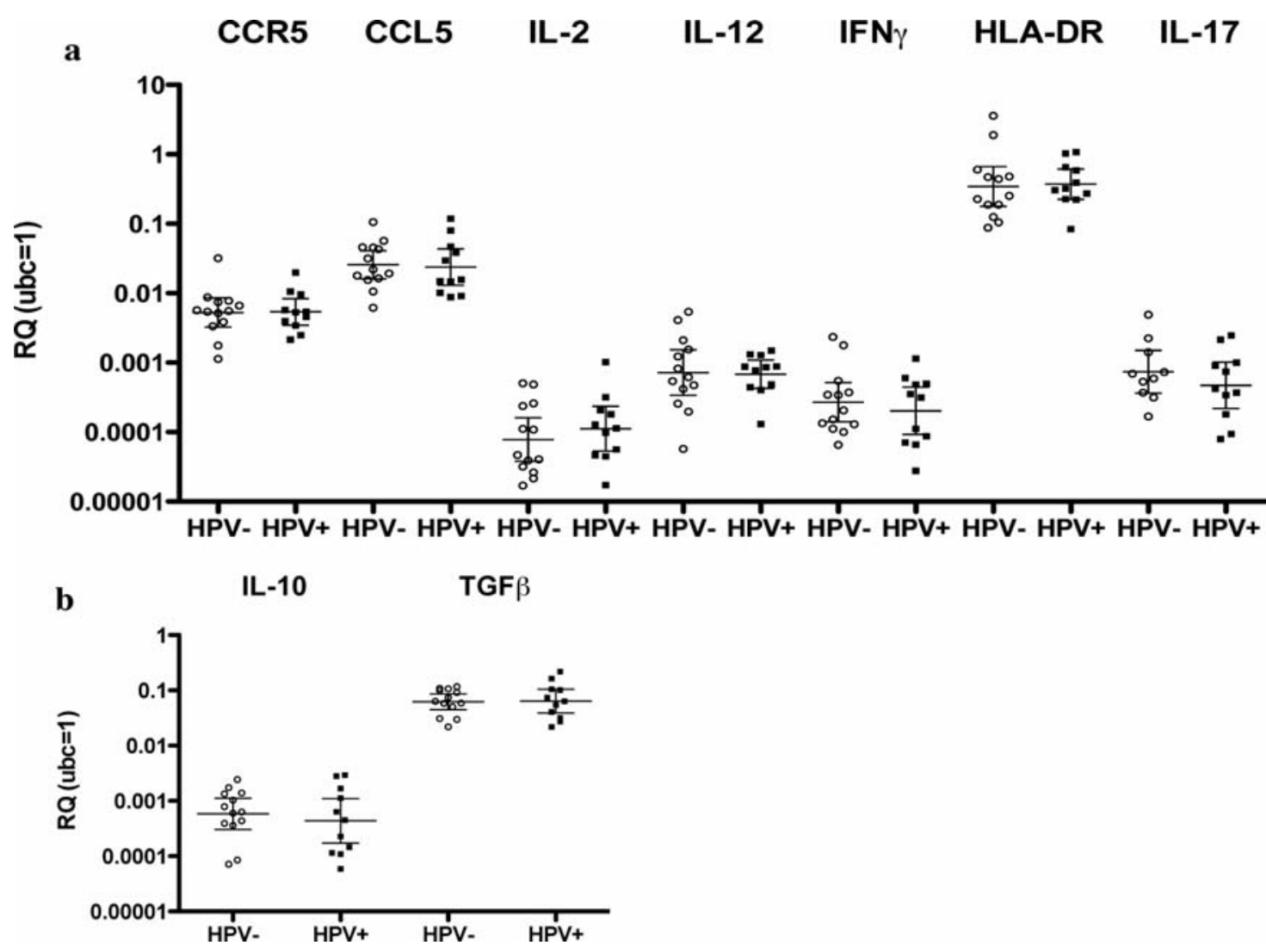

Figure 3. (a) No significant differences were found in the expression of pro-inflammatory cytokines in HPV- (circles) and $\mathrm{HPV}^{+}$(boxes) women. Lines and bars depict geometric means with 95\% confidence interval. (b) Anti-inflammatory cytokines in HPV DNA-negative and -positive women. Lines and bars depict geometric means with a 95\% confidence interval. No significant differences between HPV DNA-negative and -positive women were found.

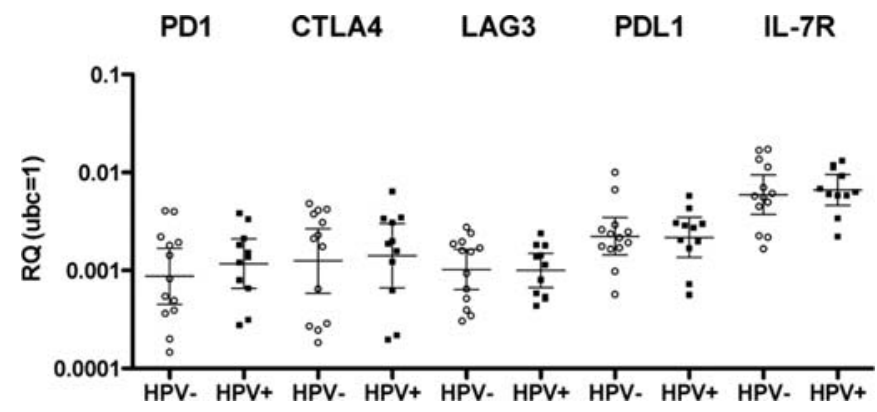

Figure 4. No significant differences were found in the expression of immunoregulatory receptors and ligands in $\mathrm{HPV}^{-}$(circles) and $\mathrm{HPV}^{+}$(boxes) women. Lines and bars depict geometric means with $95 \%$ confidence interval.

follow-up (data not shown). The anti-inflammatory cytokines TGFß, IL-4 and IL-10 were expressed in a mutually similar fashion (Fig. 3). IL-4 mRNA expression was below the detection limit in all patients. Additionally, as outlined in Fig. 4, neither immunoregulatory receptors nor ligands differed to a significant extent between HPV DNA-positive and -negative women, nor between groups of HPV status at follow-up (data not shown).

Clinical correlates of cytokines and phenotypic markers. Surveys of hormonal exposure, smoking and treatment with inhaled or oral corticosteroids, sexual and reproductive history or age (data not shown) revealed only one distinctive result, and that was mRNA expression of the phenotypic marker CD19. CD19 levels were significantly higher in women currently using oral contraception or progesterone intrauterine devices compared to women not using hormonal contraception (Fig. 5). Immunoglobulin expression was not associated with hormonal exposure. Among the other phenotypic markers, pro- or anti-inflammatory cytokines, immune regulatory receptors and corresponding ligands, there were no significant correlations with clinical parameters, including HSV seropositivity, in univariate analyses. Due to the dispersed expression of CD19 mRNA, values above or below median were analyzed in a multivariate logistic regression model combining possible confounders and effect modifiers (age, smoking, hormonal contraception, HSV status, additional inflammatory condition, new sexual encounter, HPV status at inclusion and HPV clearance). In such a model, no significant correlations were found. The two women with LSIL or ASCUS (id code nos. 21 and 24, Table II) had immune activity within the interquartile range regarding the expression of all markers. One woman (id code no. 2, Table II) had a very strong mRNA expression of CD3, CD8, CD19, CD27, IgA, IgG, PD-1, IL-7R, IFN $\gamma$ and CCR5, despite lack of clinical or laboratory signs of inflammation or infection.

\section{Discussion}

Results from this study provide a unique baseline of the constituent mRNA expression for a panel of cytokines and 


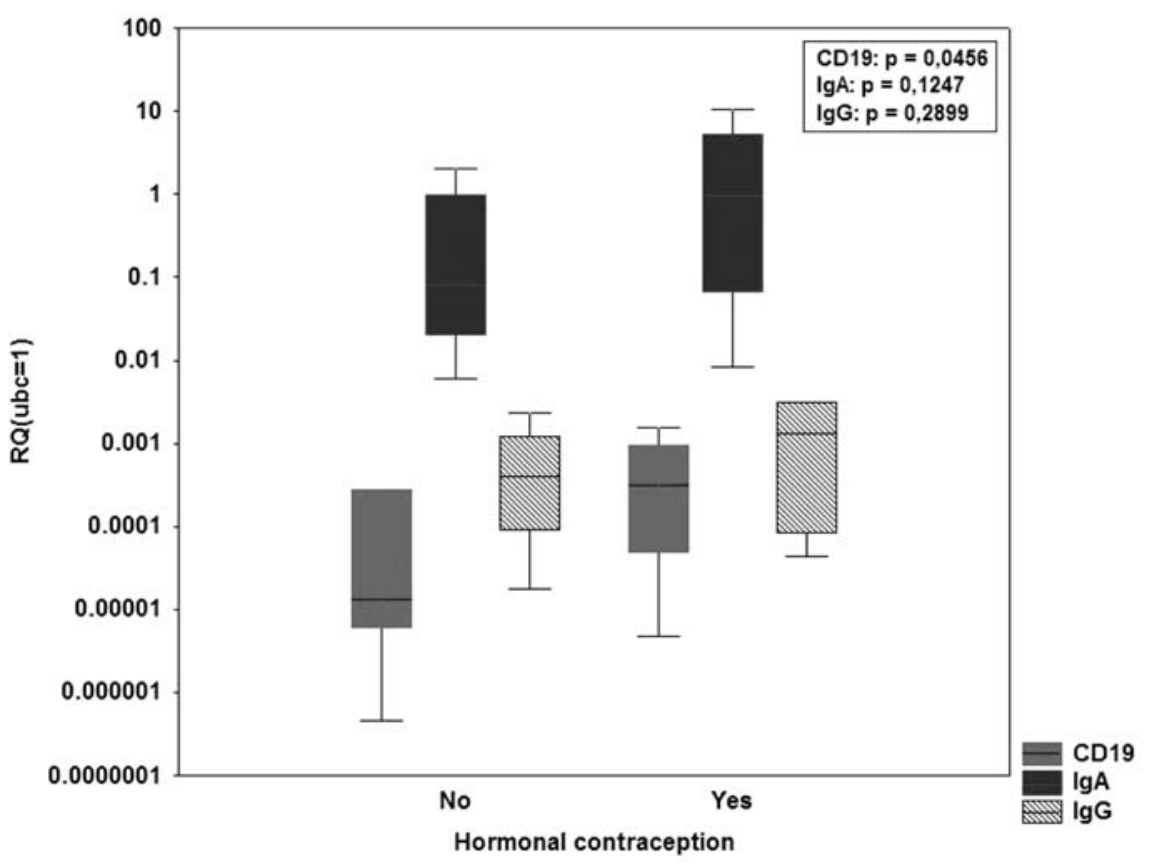

Figure 5. Expression of CD19 and immunoglobulins in women without and with current hormonal contraception (contraceptive pill or hormonal IUD). P-values were calculated with Mann-Witney U non-parametric test. Lines depict median values, boxes 25-75\% range, and whiskers denote non-outlier range.

cellular markers in the ectocervices of subjectively healthy volunteers with asymptomatic HPV infection. No differences were found in this material in inflammatory or adaptive immune response regulation, suggesting that HPV DNA positivity with high- or low-risk types without dysplastic lesions does not affect the activity of the local mucosal immune response at the mRNA level. Yet, we did observe a significant association between exposure to hormonal contraception and higher CD19 mRNA expression.

Few cytokines have been studied in cervical samples from women without CIN and no correlation with current HPV infection has been found $(18,19)$, which supports our results. In women with HPV16-positive CIN, El-Sherif et al observed decreased levels of IFN $\gamma$ and TGFß mRNA and increases of IL-10 compared to healthy HPV-negative controls $(36,37)$. Others recently found that elevations in IFN $\gamma$ and IL-10 were associated with decreased odds of having CIN 2 or $3(38,39)$. Using immunohistochemistry, Behbahani et al located more IL-2 and IL-4 expressing cells as signs of immune activation in HPV-positive women compared to negative controls (22). Immunohistochemistry enables identification of cells expressing a certain target molecule, whereas quantitative RT-PCR will detect the amount of mRNA expressed, which may or may not be related to the number of cells. In the context of HIV susceptibility, the amount of target molecules such as CD4 and CCR5 may be of greater importance than the number of cells. The essence is that asymptomatic HPV infection alone does not seem to evoke a measurable inflammatory response or attract possible HIV target cells, instead oncogenic transformation or additional immunogenic conditions may be needed.

We assessed other covariates of cytokine expression, but could not repeat previous observations of increased IL-10, IL-12 or IFN $\gamma$ mRNA expression in women with current or recent use of oral contraceptives $(18,19)$. We did however observe higher levels of CD19 mRNA in women engaged in hormonal contraception. CD19 is a phenotypic B cell marker lost in the late stages of B lymphocyte differentiation. CD19+ lymphocytes have previously been located in follicle-like structures in the subepithelial layers of the ectocervical mucosa with immunohistochemical technology (40), supporting our finding of CD19 mRNA in the ectocervix. Endometrial aggregates of $\mathrm{CD} 19^{+}$lymphocytes increase in size during mid-cycle and the secretory phase of the menstrual cycle (41), supporting the finding of hormonal influence on CD19+ cells. We did not observe any correlation between hormonal contraception and immunoglobulin mRNA expression. One may speculate that high levels of CD19 and no change in IgG or IgA expression represent hormonally blocked B lymphocyte maturation and, eventually, an impaired adaptive immunological response. In agreement with this, we noted that CD19 mRNA levels above the median correlated with chronic HPV infection ( $p=0.06)$. Combined oral contraception has long been regarded as an independent risk factor for HPV infection, CIN and cervical cancer (reviewed in ref. 42). However, that conclusion has been questioned, partly because no underlying mechanisms is evident and partly due to confounding effects by higher prevalence of HPV infection in oral contraception users (43). Here, we provide one clue to understanding how hormonal contraception may influence host immune defence, i.e., the influence of CD19 amplification.

Most cytokines, phenotypic cell markers, immunoregulatory receptors and ligands analyzed here have never before been characterized in the cervical mucosa. To determine whether the immune milieu was associated with subsequent clearance or persistence of HPV, the women were assessed for HPV diagnosis and clinical follow-up at 23.8 months following the baseline sample. Seven women were thus identified who either failed to clear their HPV infection or acquired a new HPV type, and 5 women who succeeded in 
HPV clearance. Immunological host factors significantly associated with HPV persistence or clearance could not be identified. There was however a trend of CD19 mRNA levels above median being associated with type-specific HPV persistence which is subject to further investigations. We considered the possibility of false HPV DNA negativity in the liquid-based cytology sample of one case (id code no. 2) with several signs of inflammatory activation in the cervical biopsy. However, the test was negative for HPV DNA at inclusion as well as at follow-up, and the sensitivity of Linear Array is very high $(44,45)$. None of the women had a clinically overt lesion; thus, we may not have taken the biopsy at the site of infection/inflammation. In addition, epithelial mRNA expression may dilute out differences in the immunologic microenvironment. Thus, future studies should consider including biopsies from several sites of the ectocervix and perform mRNA quantification on microdissections of such biopsies. The limited sample size of 24 women may also have hampered our ability to detect a small difference between groups. Nevertheless, major differences may be visible even between small groups of women. Most importantly the present study will serve as a pilot study.

In the present study, we have measured the mRNA expression of cytokines, phenotypic immune cell markers, immunoregulatory receptors and ligands, and immunoglobulins involved in mucosal immunity within the ectocervix of HPVpositive and -negative women. The fact that no significant differences were found in the two groups of women suggests that the immune response may not be activated in the cervices of HPV-positive women without CIN. The level of mRNA expression of these substances was neither predictive of HPV clearance, although the association between B cell maturation and persistent HPV infection is worth further exploration.

\section{Acknowledgements}

We thank Jacob Bergström and Magnus Backheden at Karolinska Institutet for professional statistical advice, as well as Professor Jan Andersson for scientific input and Joshua Fink for sharing his knowledge in the RT-PCR technique. This work was supported by grants from the Swedish Cancer Society (CAN2007/1044), the Swedish Research Council, and the Medical Research Council, as well as the Cancer Society in Stockholm, the Stockholm County Council and AFA Insurance.

\section{References}

1. Walboomers JM, Jacobs MV, Manos MM, et al: Human papillomavirus is a necessary cause of invasive cervical cancer worldwide. J Pathol 189: 12-19, 1999.

2. Zur Hausen H: Papillomaviruses causing cancer: evasion from host-cell control in early events in carcinogenesis. J Natl Cancer Inst 92: 690-698, 2000.

3. Syrjanen K HM, Saarikoski S, Vayrynen M, et al: Prevalence, incidence, and estimated life-time risk of cervical human papillomavirus infections in a nonselected Finnish female population. Sex Transm Dis 17: 15-19, 1990.

4. Koutsky LA HK, Critchlow CW, Stevens CE, et al: A cohort study of the risk of cervical intraepithelial neoplasia grade 2 or 3 in relation to papillomavirus infection. N Engl J Med 327: 1272-1278, 1992 .
5. Bosch FX, Burchell AN, Schiffman M, et al: Epidemiology and natural history of human papillomavirus infections and type-specific implications in cervical neoplasia. Vaccine 26 (Suppl. 10): K1-K16, 2008.

6. Palefsky JM and Holly EA: Chapter 6: Immunosuppression and co-infection with HIV. J Natl Cancer Inst Monogr 31: 41-46, 2003.

7. Grulich AE, van Leeuwen MT, Falster MO and Vajdic CM: Incidence of cancers in people with HIV/AIDS compared with immunosuppressed transplant recipients: a meta-analysis. Lancet 370: 59-67, 2007.

8. Scott M, Stites DP and Moscicki AB: Th1 cytokine patterns in cervical human papillomavirus infection. Clin Diagn Lab Immunol 6: 751-755, 1999.

9. Scott M, Nakagawa M and Moscicki AB: Cell-mediated immune response to human papillomavirus infection. Clin Diagn Lab Immunol 8: 209-220, 2001.

10. Song SH, Lee JK, Lee NW, Saw HS, Kang JS and Lee KW: Interferon-gamma (IFN-gamma): a possible prognostic marker for clearance of high-risk human papillomavirus (HPV). Gynecol Oncol 108: 543-548, 2008.

11. Coleman N, Birley HD, Renton AM, et al: Immunological events in regressing genital warts. Am J Clin Pathol 102: 768-774, 1994.

12. Kadish AS, Timmins P, Wang Y, et al: Regression of cervical intraepithelial neoplasia and loss of human papillomavirus (HPV) infection is associated with cell-mediated immune responses to an HPV type 16 E7 peptide. Cancer Epidemiol Biomarkers Prev 11: 483-488, 2002.

13. Overbergh L, Giulietti A, Valckx D, Decallonne R, Bouillon R and Mathieu C: The use of real-time reverse transcriptase PCR for the quantification of cytokine gene expression. J Biomol Tech 14: 33-43, 2003.

14. Coffman RL, Varkila K, Scott P and Chatelain R: Role of cytokines in the differentiation of $\mathrm{CD}^{+} \mathrm{T}$-cell subsets in vivo. Immunol Rev 123: 189-207, 1991.

15. Mosmann TR: Cytokine secretion patterns and cross-regulation of T cell subsets. Immunol Res 10: 183-188, 1991.

16. Gaffen SL: An overview of IL-17 function and signaling. Cytokine 43: 402-407, 2008

17. Patterson BK, Landay A, Andersson J, et al: Repertoire of chemokine receptor expression in the female genital tract: implications for human immunodeficiency virus transmission. Am J Pathol 153: 481-490, 1998.

18. Gravitt PE, Hildesheim A, Herrero R, et al: Correlates of IL-10 and IL-12 concentrations in cervical secretions. J Clin Immunol 23: 175-183, 2003.

19. Scott ME, Ma Y, Farhat S, Shiboski S and Moscicki AB: Covariates of cervical cytokine mRNA expression by real-time PCR in adolescents and young women: effects of Chlamydia trachomatis infection, hormonal contraception, and smoking. J Clin Immunol 26: 222-232, 2006.

20. Crowley-Nowick PA, Ellenberg JH, Vermund SH, Douglas SD, Holland CA and Moscicki AB: Cytokine profile in genital tract secretions from female adolescents: impact of human immunodeficiency virus, human papillomavirus, and other sexually transmitted pathogens. J Infect Dis 181: 939-945, 2000.

21. Nicol AF, Fernandes AT, Grinsztejn B, et al: Distribution of immune cell subsets and cytokine-producing cells in the uterine cervix of human papillomavirus (HPV)-infected women: influence of HIV-1 coinfection. Diagn Mol Pathol 14: 39-47, 2005.

22. Behbahani H, Walther-Jallow L, Klareskog E, et al: Proinflammatory and type 1 cytokine expression in cervical mucosa during HIV-1 and human papillomavirus infection. J Acquir Immune Defic Syndr 45: 9-19, 2007.

23. Li J, Huston G and Swain SL: IL-7 promotes the transition of CD4 effectors to persistent memory cells. J Exp Med 198: 1807-1815, 2003.

24. Hand TW, Morre M and Kaech SM: Expression of IL-7 receptor alpha is necessary but not sufficient for the formation of memory CD8 T cells during viral infection. Proc Natl Acad Sci USA 104: 11730-11735, 2007.

25. Sharpe AH, Wherry EJ, Ahmed R and Freeman GJ: The function of programmed cell death 1 and its ligands in regulating autoimmunity and infection. Nat Immunol 8: 239-245, 2007.

26. Velu V, Titanji K, Zhu B, et al: Enhancing SIV-specific immunity in vivo by PD-1 blockade. Nature 458: 206-210, 2009.

27. Blackburn SD, Shin H, Haining WN, et al: Coregulation of $\mathrm{CD}^{+} \mathrm{T}$ cell exhaustion by multiple inhibitory receptors during chronic viral infection. Nat Immunol 10: 29-37, 2009. 
28. Agematsu K, Hokibara S, Nagumo H and Komiyama A: CD27: a memory B-cell marker. Immunol Today 21: 204-206, 2000.

29. Schluns KS and Lefrancois L: Cytokine control of memory T-cell development and survival. Nat Rev Immunol 3: 269-279, 2003.

30. Jackson SM, Wilson PC, James JA and Capra JD: Human B cell subsets. Adv Immunol 98: 151-224, 2008.

31. Monnier-Benoit S, Mauny F, Riethmuller D, et al: Immunohistochemical analysis of $\mathrm{CD}^{+}$and $\mathrm{CD}^{+} \mathrm{T}$-cell subsets in high risk human papillomavirus-associated pre-malignant and malignant lesions of the uterine cervix. Gynecol Oncol 102: 22-31, 2006

32. Solomon D, Davey D, Kurman R, et al: The 2001 Bethesda System: terminology for reporting results of cervical cytology. JAMA 287: 2114-2119, 2002.

33. Froberg M, Johansson B, Hjerpe A and Andersson S: Human papillomavirus 'reflex' testing as a screening method in cases of minor cytological abnormalities. Br J Cancer 99: 563-568, 2008.

34. Muñoz N, Bosch FX, de Sanjosé S, et al: Epidemiologic classification of human papillomavirus types associated with cervical cancer. N Engl J Med 348: 518-527, 2003.

35. Livak KJ and Schmittgen TD: Analysis of relative gene expression data using real-time quantitative PCR and the 2(-Delta Delta C(T)) method. Methods 25: 402-408, 2001.

36. El-Sherif AM, Seth R, Tighe PJ and Jenkins D: Decreased synthesis and expression of TGF-beta1, beta2, and beta3 in epithelium of HPV 16-positive cervical precancer: a study by microdissection, quantitative RT-PCR, and immunocytochemistry. J Pathol 192: 494-501, 2000.

37. El-Sherif AM, Seth R, Tighe PJ and Jenkins D: Quantitative analysis of IL-10 and IFN-gamma mRNA levels in normal cervix and human papillomavirus type 16 associated cervical precancer. J Pathol 195: 179-185, 2001.
38. Scott ME, Ma Y, Kuzmich L and Moscicki AB: Diminished IFN-gamma and IL-10 and elevated Foxp3 mRNA expression in the cervix are associated with CIN 2 or 3. Int J Cancer 124: 1379-1783, 2009

39. Syrjanen S, Naud P, Sarian L, et al: Immunosuppressive cytokine interleukin-10 (IL-10) is up-regulated in high-grade CIN but not associated with high-risk human papillomavirus (HPV) at baseline, outcomes of HR-HPV infections or incident CIN in the LAMS cohort. Virchows Arch 455: 505-515, 2009.

40. Johansson EL, Rudin A, Wassen L and Holmgren J: Distribution of lymphocytes and adhesion molecules in human cervix and vagina. Immunology 96: 272-277, 1999.

41. Yeaman GR, Guyre PM, Fanger MW, et al: Unique CD8 ${ }^{+} \mathrm{T}$ cell-rich lymphoid aggregates in human uterine endometrium. J Leukoc Biol 61: 427-435, 1997.

42. Castellsague X and Munoz N: Chapter 3: Cofactors in human papillomavirus carcinogenesis-role of parity, oral contraceptives, and tobacco smoking. J Natl Cancer Inst Monogr 31: 20-28, 2003.

43. Syrjänen K, Shabalova I, Petrovichev N, et al: Oral contraceptives are not an independent risk factor for cervical intraepithelial neoplasia or high-risk human papillomavirus infections. Anticancer Res 26: 4729-4740, 2006.

44. Giuliani L, Coletti A, Syrjanen K, Favalli C and Ciotti M: Comparison of DNA sequencing and Roche Linear array in human papillomavirus (HPV) genotyping. Anticancer Res 26: 3939-3941, 2006.

45. Monsonego J, Pollini G, Evrard MJ, et al: Detection of human papillomavirus genotypes among high-risk women: a comparison of hybrid capture and linear array tests. Sex Transm Dis 35: 521-527, 2008. 